\title{
Cardiovascular surgery for congenital heart disease associated with trisomy 18
}

\author{
Hiroyuki Yamagishi, MD, PhD
}

Received: 11 May 2009

(C) The Japanese Association for Thoracic Surgery 2010

Trisomy 18 (T18) is the second most common autosomal trisomy after trisomy 21 (T21). More than $90 \%$ of patients with T18 have congenital heart disease (CHD). Patients with T18 also have multiple malformations and severe psychomotor retardation, and their 1-year survival rate is $5 \%-10 \% .{ }^{1}$ No criteria for surgical treatment of CHD in patients with T18 have been established.

The prognosis of patients with T21 has been significantly improved as surgical treatment of CHD for these patients has become common. However, the prognosis of patients with T18 is still poor, and it has been believed that surgical treatment does not improve their survival. Thus, CHD in this patient population has been managed conservatively. However, since 1990s, cases of heart surgery in patients with T18 have been reported in and outside Japan, ${ }^{2,3}$ and Graham et al. have evaluated the outcome of surgery in many patients with $\mathrm{T} 18^{4}$ (Table 1). Recently, indications for surgical treatment of CHD in patients with T18 have been discussed more extensively. In patients with $\mathrm{T} 18$, the risk of complications associated with surgical treatment of CHD is high, as is the risk of early death due to causes other than CHD. Because no well-defined criteria for heart surgery are available for patients with T18, physicians often experience difficulty when determining whether heart surgery

This editorial refers to the article by Kobayashi et al. on pp. 223 227 of this issue of General Thoracic and Cardiovascular Surgery.

H. Yamagishi $(\bowtie)$

Department of Pediatrics (Division of Pediatric Cardiology),

Keio University School of Medicine, 35 Shinanomachi,

Shinjyuku-ku, Tokyo 160-8582, Japan

Tel. +81-3-3353-1211; Fax +81-3-5379-1978

e-mail: hyamag@sc.itc.keio.ac.jp should be performed. In reports advocating surgical treatment of CHD for patients with T18, including that by Kobayashi et al. in this issue, ${ }^{6}$ authors have suggested that surgical treatment, when performed with full understanding of the disease by the parents and with their hope for improving their children's condition, may contribute to improving the life expectancy of patients, discharge from hospital, and improving the quality of life (QOL) of both patients and their family.

Opinions supportive of aggressive surgical treatment of CHD for patients with T18 may be based on recent advances in neonatal care. Kosho et al. reported that mechanical ventilation, surgical correction of gastrointestinal and respiratory complications, and active medical treatment of CHD in 24 patients with T18 improved the 1-year survival to $25 \%{ }^{7}$ Although these 24 patients did not undergo heart surgery, the findings suggest that multimodality therapy for complications related to T18 may improve at least short-term survival. However, such reports remain scanty. A larger number of cases must be accumulated, as in the above-mentioned report by Kobayashi et al, ${ }^{6}$ for development of guidelines for treating these patients.

The Genetics \& Epidemiology Committee of the Japan Society of Pediatric Cardiology and Cardiac Surgery, of which the author is the chairperson, developed a survey plan to investigate the conditions of patients with T18 in Japan. Some of the results obtained from 15 institutions by the end of 2008 are briefly summarized as follows.

- Characteristics of patients with T18: Data were obtained for 135 patients (46 males, 87 females, 2 children with unreported sex) with ages ranging from day 0 to 19.9 years (median 4.8 months), birth weight 
Table 1 Reported cases of cardiovascular surgery in infants with trisomy 18

\begin{tabular}{|c|c|c|c|c|}
\hline CHD & Palliative surgery & $\begin{array}{l}\text { Open-heart corrective } \\
\text { surgery }\end{array}$ & Result & Reference \\
\hline \multicolumn{5}{|l|}{ Case reports } \\
\hline VSD, PS & & ICR (2 year) & $\begin{array}{l}\text { Died of irreversible } \\
\text { congestive heart failure } \\
\text { after surgery }\end{array}$ & Van Dyke, ${ }^{2} 1990$ \\
\hline VSD, PDA & & ICR (2 years) & $\begin{array}{l}\text { Alive more than } 5 \text { years } \\
\text { after surgery, attending } \\
\text { school, able to stand with } \\
\text { support and to feed self }\end{array}$ & Van Dyke, ${ }^{2} 1990$ \\
\hline CoA, DORV, PDA & $\begin{array}{l}\text { PDA ligation, aortoplasty } \\
\text { (4 months) }\end{array}$ & $\begin{array}{l}\text { ICR: DORV repair } \\
\text { (14 months) }\end{array}$ & Died during surgery & Baty, ${ }^{3} 1994$ \\
\hline \multirow{2}{*}{$\begin{array}{c}\text { Report of } 35 \text { cases with } \\
\text { trisomy } 18 / 13\end{array}$} & PAB ( 9 cases $)$ & ICR (18 cases) & \multirow{5}{*}{$\begin{array}{l}\text { Discharged alive ( } 32 \text { cases) } \\
28 \text { to home } \\
4 \text { to referral institution }\end{array}$} & \multirow[t]{14}{*}{ Graham, ${ }^{4} 2004$} \\
\hline & 4 VSD before ICR & $12 \mathrm{VSD}$ & & \\
\hline Trisomy 18 (24 cases) & 3 VSD with no ICR & $3 \mathrm{CoA}$ & & \\
\hline VSD 14 & $1 \mathrm{CoA}$ & $2 \mathrm{TOF}$ & & \\
\hline TOF 5 & 1 AVSD & 1 AVSD & & \\
\hline CoA 2 & SP shunt (4 cases) & PDA ligation ( 3 cases) & \multirow{9}{*}{$\begin{array}{l}\text { Dead ( } 3 \text { cases) } \\
11 \text { days, just after VSD } \\
\text { repair } \\
5 \text { years; } 46 \text { days after TOF } \\
\text { repair } \\
6 \text { years; } 9 \text { days palliation } \\
\text { for TOF }\end{array}$} & \\
\hline PDA 2 & $4 \mathrm{TOF}$ & & & \\
\hline AVSD 1 & PDA ligation ( 1 case) & & & \\
\hline Trisomy 13 (11 cases) & (VSD/PDA) & & & \\
\hline VSD 6 & & & & \\
\hline TOF 1 & & & & \\
\hline $\mathrm{CoA} 2$ & & & & \\
\hline PDA 1 & & & & \\
\hline AVSD 1 & & & & \\
\hline
\end{tabular}

Modified from Suzuki et al. ${ }^{5}$

CHD, congenital heart disease; VSD, ventral septal defect; PS, pulmonary stenosis; PDA, patent ductus arteriosus; ICR, intracardiac repair; CoA, coarctation of the aorta; TOF, tetralogy of Fallot; AVSD, atrioventricular septal defect; PAB, premature atrial beat

650-2698 g (median $1692 \mathrm{~g}$ ), and length of gestation of 28-48 weeks (median 37).

- Characteristics of CHD: In all, 127 patients (95\%) had CHD. Ventricular septal defect was most common (75 patients, 58\%) followed by double-outlet right ventricle (DORV) (15 patients, 11\%). DORV with left-toright shunt without pulmonary stenosis accounted for $73 \%$ of the patients with DORV; and mitral atresia, an anomaly typically associated with $\mathrm{T} 18,{ }^{8}$ was observed in 4 patients with DORV (27\%). Of the 127 patients with CHD, $76(60 \%)$ had pulmonary hypertension induced by high pulmonary blood flow due to left-to-right shunt. Valvular lesions were observed in 56 of the 127 patients (47\%), including 32 patients with multiple valvular lesions, 13 of whom had lesions of all four valves.

- Surgical treatment of CHD: A total of 34 patients (27\%) underwent surgery: 19 patients survived (56\%) whereas 15 patients $(44 \%)$ died after surgery, including 2 patients who died within 1 month after surgery. Age at surgery ranged from 1 day to 18.6 months (median 1.8 months). Pulmonary hypertension was present before surgery in 31 patients $(91 \%)$ and was alleviated after surgery in 17 patients $(55 \%)$. Surgical techniques included palliative operation in 23 patients
$(68 \%)$ and intracardiac repair in 6 patients $(18 \%)$; it was unknown for 5 patients. Of the 23 patients, 16 $(70 \%)$ had undergone a palliative operation; and three of the six $(50 \%)$ patients who had undergone intracardiac repair were alive at the time of investigation. Palliative operations performed in the 23 patients included pulmonary artery banding in 18 patients, aortoplasty and pulmonary artery banding for the treatment of complex aortic coarctation in 3 patients, and systemic-to-pulmonary shunt for the treatment of cyanotic heart disease in 2 patients.

- Outcome and causes of death: At the time of survey, 24 patients (18\%) were alive, including 5 males and 19 females with a median age of 2.4 years and a maximum age of 19.9 years. The most common reasons for death in the 97 patients with known causes of death were respiratory failure (25 patients) and heart failure (24 patients). Sudden death was also common (15 patients). The 2-year survival rates for patients who had undergone or not undergone surgical treatment for CHD were $45 \%$ and $5 \%$, respectively. Although it appears that surgery improves survival in the above-described patient population, it is likely that the patients undergoing surgery had relatively mild CHD or extracardiac complications correctable with surgical treatment. 
Accordingly, although cardiac surgery may be indicated for patients with relatively mild CHD or extracardiac complications, it is still unclear whether heart surgery improves the long-term prognosis of patients with T18.

As described in the report by Kobayashi et al, ${ }^{6}$ technical difficulties encountered when performing surgical treatment of CHD in patients with T18 are being overcome. However, the opinions of parents and families of patients should be strongly respected in determining whether such surgery should be performed. Physicians should provide information to the family sufficient to enable optimal decision-making. Discussion with the family should be performed using the literature, results of the committee's survey, information provided by the Trisomy 18 Patient Group, and other available sources. At present, pediatric cardiologists should, at a minimum, explain the following.

1. The severity of CHD and indications for surgical treatment differ among patients with T18. Individual evaluation is needed to determine optimal treatment.

2. It is still unknown whether heart surgery improves the prognosis of patients with T18.

3. The risk of surgery is higher in patients with T18 than in patients without trisomy or patients with T21.

4. Because the number of patients with T18 who have undergone surgery is still small, unexpected complications may occur.

5. Complications other than CHD may affect prognosis and QOL after surgery.

6. Finally, heart surgery may improve life expectancy, facilitate discharge from the hospital, and improve QOL of both patient and family.

Even when sufficient information is provided, the parents, who must determine important treatment strategies for their newborn child, are under severe emotional stress. If physicians provide information alone and let the family to determine what should be done for their child, the parents may be placed in a difficult position. Even if the patient can be discharged from the hospital after surgery, the family may often be overwhelmed by care for the child, who will require respiratory support including tracheostomy care and have severe mental retardation. The attending physicians must provide appropriate, medically informed opinions based on expectations regarding prognosis and their experience and knowledge as well as ethical considerations. If issues cannot be resolved by the pediatric cardiologists alone, they should seek the aid of clinical geneticists when performing interviews and genetic counseling sessions to support understanding and decision-making by the family.

\section{References}

1. Embleton ND, Wyllie JP, Wright MJ, Burn J, Hunter S. Natural history of trisomy 18. Arch Dis Child Fetal Neonatal Ed 1996;75:F38-41.

2. Van Dyke DC, Allen M. Clinical management considerations in long-term survivors with trisomy 18. Pediatrics 1990;85: 753-9.

3. Baty BJ, Blackburn BL, Carey JC. Natural history of trisomy 18 and trisomy 13. I. Growth, physical assessment, medical histories, survival, and recurrence risk. Am J Med Genet 1994;49:175-88.

4. Graham EM, Bradley SM, Shirali GS, Hills CB, Atz AM. Effectiveness of cardiac surgery in trisomies 13 and 18 (from the Pediatric Cardiac Care Consortium). Am J Cardiol 2004;93:801-3.

5. Suzuki E, Oshima Y, Doi Y, Ohtaka S, Hashimoto I, Ichida F, et al. Four cases of open-heart surgery in infants with trisomy 13 or trisomy 18. Pediatr Cardiol Cardiovasc Surg 2008;24:54654 (in Japanese).

6. Kobayashi J, Kaneko Y, Yamamoto Y, Yoda H, Tsuchiya K. Radical surgery for ventricular septal defect associated with trisomy 18. This issue.

7. Kosho T, Nakamura T, Kawame H, Baba A, Tamura M, Fukushima Y. Neonatal management of trisomy 18: clinical details of 24 patients receiving intensive treatment. Am J Med Genet A 2006;140:937-44.

8. Van Praagh S, Trumen T, Firpo A, Bano-Rogriga A, Freid R, McManis B, et al. Cardiac malformations in trisomy-18: a study of 41 postmortem cases. J Am Coll Cardiol 1989;13: 1586-97. 